ARTIGO

\title{
Desenvolvimento profissional docente em tempos de neoliberalismo acadêmico: o que pensam professores enfermeiros
}

\author{
Kátia Pereira de Borba' (1D \\ Maria José Clapis" (1D
}

RESUMO

Partindo-se da premissa que o desenvolvimento profissional docente tem profunda relação com o exercício da docência, realizou-se um estudo de caso naturalístico, que objetivou analisar a percepção de professores enfermeiros atuantes em um curso de Enfermagem de uma Universidade Pública, sobre os aspectos que envolvem o desenvolvimento profissional docente e o exercício da docência. Os dados foram coletados através de entrevista semiestruturada, mediante aprovação por Comitê de Ética em Pesquisa, em que participaram 30 professores. Verificou-se que os professores enfermeiros entendem a função primordial da universidade pública como uma instituição social, consentem com a sua função hegemônica contemporânea, enquanto organização social e percebem a sua estrutura física, como elemento contribuinte para o desenvolvimento profissional docente. Compreendeu-se que o desenvolvimento profissional docente de professores enfermeiros universitários exerce influência sobre o exercício da docência.

PALAVRAS-CHAVE

ensino; educação em enfermagem; docente de enfermagem; prática do docente de enfermagem. 


\title{
TEACHER PROFESSIONAL DEVELOPMENT IN TIMES OF ACADEMIC NEOLIBERALISM: WHAT NURSING TEACHERS THINK
}

\begin{abstract}
Starting from the premise that the professional development of teachers has a profound relationship with the exercise of teaching, a naturalistic case study was carried out, which aimed to analyze the perception of nursing professors working in a Nursing course at a Public University, on the aspects that involve the professional development of teachers and the exercise of teaching. The data were collected through a semi-structured interview, with approval by the Research Ethics Committee. 30 teachers participated. It was found that the nurse professors understand the primary function of the public university as a social institution, they consent to their contemporary hegemonic function as a social organization, and perceive its physical structure as a contributing element to the professional development of teachers. It was understood that the professional development of nursing professors in a university has an influence on the exercise of teaching.
\end{abstract}

\section{KEYWORDS}

teaching; nursing education; nursing teacher; nursing teacher practice.

\section{DESARROLLO PROFESIONAL DEL PROFESORADO EN TIEMPOS DE NEOLIBERALISMO ACADÉMICO: LO QUE PIENSAN LOS PROFESORES DE ENFERMERIA}

\section{RESUMEN}

Partiendo de la premisa de que el desarrollo profesional docente tiene una profunda relación con el ejercicio de la docencia, se llevó a cabo un estudio de caso naturalista, cuyo objetivo era analizar la percepción de los profesores de enfermería que trabajan en un curso de enfermería en una universidad pública, sobre los aspectos que implican el desarrollo profesional docente y el ejercicio de la enseñanza. Los datos fueron recolectados a través de entrevistas semiestructuradas, mediante la aprobación del Comité de Ética en Investigación, en las que participaron 30 profesores. Se ha verificado que los profesores de enfermería entienden la función primordial de la universidad pública como institución social, acceden a su función hegemónica contemporánea, mientras organización social, y perciben su estructura física como un elemento que contribuye al desarrollo profesional docente. Se entendió que el desarrollo profesional docente de profesores universitarios de enfermería influye en el ejercicio de la docencia.

\section{PALABRAS CLAVE}

docencia; educación en enfermería; docente de enfermería; práctica del profesor de enfermería. 


\section{INTRODUÇÃO}

O desenvolvimento profissional docente (DPD) é um processo individual e coletivo, que se concretiza no local de trabalho do professor, e envolve diferentes tipos de oportunidades e experiências. É construído ao longo da carreira docente e pode ser influenciado pela instituição de ensino e contextos políticos (García, 1999; García e Vaillant, 2016). Tem íntima relação epistemológica com áreas da teoria e investigação da didática. Inclui a organização da instituição de ensino e do currículo onde os professores atuam; o ensino e as estruturas sociais, acadêmicas e cognitivas que envolvem o processo de ensinar; e a profissionalidade que, relacionada à carreira docente, implica nas expectativas da profissão, nas oportunidades de cursos de formação, bem como nas condições psicológicas e sociais no exercício da docência (García, 1999).

Sobretudo, o DPD constitui a formação do professor sob uma abordagem ampliada e se faz num continuum, desde a educação familiar e cultural até a sua trajetória formal e acadêmica, mantendo-se como processo vital, enquanto acontece seu ciclo profissional (García e Vaillant, 2016). Compreender o processo do DPD em sua dimensão evolutiva favorece o entendimento das múltiplas influências que se estabelecem sobre ele (Cunha, 2013).

Com o advento do neoliberalismo, as universidades públicas brasileiras perderam a prioridade nas políticas do Estado, ficando o bem público universitário aberto à exploração comercial. Dessa forma, tornou-se uma instituição de altíssimo grau de complexidade, um tipo sofisticado e diversificado de organização social principalmente dedicado a negócios, implicada no desenvolvimento acadêmico como uma corporação, sendo a carreira acadêmica construída basicamente através de publicações e do desenvolvimento de projetos de pesquisa, em detrimento à dedicação do professor ao ensino (Dias Sobrinho, 2014; Nóvoa, 2015).

Ressalta-se que a universidade pública é uma instituição social. É uma expressão historicamente determinada de uma sociedade determinada (Chaú́, 2003). Exprime entender que tem responsabilidade sobre o modelo de desenvolvimento da sociedade global (Dias Sobrinho, 2015) e que assume um compromisso com a ética, o que significa o seu envolvimento a projetos, para além da formação de recursos humanos e da produção de conhecimentos, como questões sociais, econômicas e culturais que circundam a sociedade como um todo (UNESCO, 1998).

Em tempos de neoliberalismo, entende-se necessário preocupar-se com o DPD de professores universitários brasileiros atuantes em universidades públicas, especialmente do enfermeiro. Isso porque, exercendo a docência universitária, seu importante trabalho transversal na área do ensino de enfermagem não se reduz ao campo didático-pedagógico, mas pressupõe ofícios com distintos ramos do saber, o que exige instrumentalização diversificada, com o objetivo de formar o enfermeiro para o mundo do trabalho, profissional essencial na área da saúde, campo do conhecimento que está articulado aos contextos social, cultural, histórico e político, com os quais os seres humanos vivem e se relacionam.

A formação docente entendida como DPD vem sendo contemplada nos estudos de alguns autores da área da educação geral nacional e internacional (Zabalza, 
2013; Almeida e Pimenta, 2014; García e Vaillant, 2016), no entanto não tem sido investigada sob o âmbito do DPD na área da educação em enfermagem, o que se considerou nesse propósito uma lacuna de conhecimento digna de investigação.

As pesquisas científicas nacionais e internacionais publicadas nos últimos cinco anos com abordagem de formação docente demonstraram seu foco na preocupação com a caracterização do ensino de enfermagem intimamente absorvido pelo paradigma tradicional e biologicista (Alexandre e Cesarino, 2014; Draganov e Sanna, 2016) e na necessidade de o professor enfermeiro adquirir a capacitação pedagógica para exercer o papel de educador no ensino superior (Alexandre e Cesarino, 2014; Booth et al., 2016; Draganov e Sanna, 2016; Agnelli e Nakayama, 2018).

Assim, motivou-se a realização de um estudo envolvendo o DPD de professores enfermeiros atuantes em universidades públicas. Para isso, partiu-se da premissa que o DPD de professores enfermeiros universitários públicos tem profunda relação com o exercício da docência no ensino de enfermagem. A fim de responder o problema de interesse, elaborou-se a seguinte questão de pesquisa: Como professores enfermeiros universitários atuantes em universidade pública percebem as relações que envolvem o DPD e o exercício da docência no ensino de enfermagem?

Nessa perspectiva, este estudo teve como objetivo analisar a percepção de professores enfermeiros atuantes em universidade pública, sobre os aspectos que envolvem o DPD e o exercício da docência.

\section{METODOLOGIA}

Estudo de caso naturalístico, descritivo e exploratório de abordagem qualitativa (Lüdke e André, 2018), realizado com professores enfermeiros universitários, atuantes em um curso de Enfermagem de uma universidade pública localizada na região sudeste do Brasil.

A inclusão dos participantes no estudo caracterizou-se por amostragem qualitativa intencional, construída com base nos 32 critérios consolidados para relato de pesquisa qualitativa (Consolidated Criteria for Reporting Qualitative - COREQ), sendo participantes aqueles que compartilhavam características particulares e com potencial de fornecer dados ricos, relevantes e diversos, pertinentes à questão de pesquisa (Tong, Sainsbury e Craig, 2007).

Assim, foram critérios de inclusão: professores enfermeiros universitários com formação em enfermagem; sob regime de trabalho com dedicação integral à docência e à pesquisa, com experiência mínima de três anos; e que estivessem atuando nas disciplinas anuais ou semestrais ofertadas para os graduandos do primeiro ao quinto ano do curso de enfermagem no segundo semestre letivo do ano de 2016.

A amostragem intencional construiu-se da seguinte forma:

- Consultou-se o cronograma das disciplinas obrigatórias do curso de Bacharelado e Licenciatura em Enfermagem, atendo-se àquelas ministradas por professores enfermeiros e ofertadas no segundo semestre do ano letivo de 2016; 
- Constatou-se uma oferta de 23 disciplinas, sendo cinco no primeiro ano, cinco no segundo ano, três no terceiro ano, quatro no quarto ano e seis no quinto ano;

- Identificou-se um total de 43 professores enfermeiros envolvidos com a responsabilidade de ministrar essas disciplinas;

- Dos 43, excluíram-se dois professores, um por estar na condição de professor titular sênior ${ }^{1}$ e outro por ser orientador do estudo.

Desse modo, definiu-se a amostragem intencional com 41 professores.

Para a coleta de dados, utilizou-se entrevista semiestruturada (Minayo, 2014) contendo questões que envolveram a identificação dos professores quanto a sexo, idade, tempo de formação acadêmica, tempo de experiência profissional na docência e na assistência de enfermagem, e questões abordadas a partir do objeto de investigação, contemplando os eixos temáticos comuns ao DPD, os quais, Universidade Pública, Currículo, Ensino e Profissionalidade.

As entrevistas foram realizadas por uma das pesquisadoras, entre os meses de setembro a dezembro de 2016, nas salas individuais de trabalho dos próprios professores, de acordo com a disponibilidade dos mesmos; e gravadas, com duração mínima de 15 e máxima de sessenta minutos, estando presentes no momento somente o pesquisador e o pesquisado.

Cada investigado foi identificado pelas letras PE (Professor Enfermeiro), seguida por numeração correspondente ao número de participantes e a ordem de agendamento das entrevistas.

Para a constatação da saturação teórica dos achados das entrevistas semiestruturadas, utilizou-se a técnica de tratamento dos dados proposta por Fontanella et al. (2011):

- Disponibilizou-se o registro de dados brutos, realizando-se audições individuais dos áudios de gravação, transcrevendo-se integralmente os diálogos captados;

- Imergiu-se em cada registro, explorando-se individualmente cada uma das entrevistas, identificando-se nas falas dos participantes a composição de temas e núcleos de sentido;

- Verificou-se a possibilidade de organização de duas categorias temáticas, construídas pelo desmembramento das falas dos participantes em temas circundados por núcleos de sentido;

- Alocou-se em uma tabela os temas, nominando-os e agregando-os a cada categoria temática, observando-se quando se deu a primeira ocorrência e contando manualmente o número de vezes que apareceram;

- Constatou-se a saturação teórica dos dados, a partir do momento que novos temas não foram acrescentados na ocorrência de diferentes entrevistas, após a realização da $12^{\mathrm{a}}$ entrevista na categoria temática 1 e da $22^{\mathrm{a}}$ entrevista na categoria 2 .

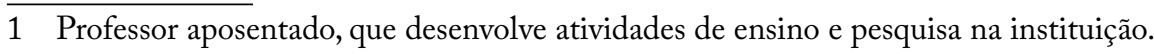


Os dados foram analisados através da análise de conteúdo, na modalidade temática (Minayo, 2014), sendo referencial de base o teórico Carlos Marcelo García. Após a realização da pré-análise e da leitura exaustiva e compreensiva do material selecionado, e tratamento dos resultados, analisou-se os diferentes núcleos de sentido presentes nos vários temas. Elaborou-se uma redação por tema, de modo a dar conta dos sentidos dos textos e de sua articulação com os conceitos teóricos que orientaram a análise, sendo que nessa redação entremearam-se partes dos textos de análise com conclusões próprias, dados de outros estudos e conceitos teóricos.

A pesquisa somente aconteceu após aprovação do Comitê de Ética em Pesquisa de uma universidade pública, sob o parecer 271/2016.

\section{RESULTADOS E DISCUSSÃO}

Dos 41 professores enfermeiros doutores convidados, 30 participaram do estudo. Dez justificaram não poder participar; dois por motivos de saúde, e oito por não haver momento para agendar a entrevista. Um professor não respondeu aos e-mails, nem ao contato telefônico.

A caracterização dos participantes preponderou mulheres adultas, com tempo de formação acadêmica superior a dez anos, e com experiência profissional na docência e na assistência de enfermagem há mais de cinco anos.

O predomínio de informações nos relatos do grupo investigado (85 a 95\%) permitiu identificar elementos comuns ao DPD, o que compreendeu a composição das categorias temáticas:

- A organização da universidade pública como elemento inerente ao desenvolvimento profissional docente;

- O DPD e as atividades acadêmicas e didáticas que envolvem o exercício da docência no ensino de enfermagem.

\section{A ORGANIZAÇÃO DA UNIVERSIDADE PÚBLICA COMO ELEMENTO INERENTE AO DESENVOLVIMENTO PROFISSIONAL DOCENTE}

A responsabilidade primeira de uma universidade é cumprir suas atividades de formação, e de trato com o conhecimento com o maior grau possível de qualidade acadêmica, científica, técnica, moral, política e social, consistindo essencialmente na formação de indivíduos-cidadãos dotados de valores cívicos e conhecimentos técnicos cientificamente relevantes e socialmente pertinentes (Dias Sobrinho, 2015). Enquanto universidade pública, deve ser caracterizada como instituição social, dado que, seu universo ideológico é a sociedade (Chauí, 2003), o que a compele à responsabilidade social.

A responsabilidade social de uma universidade compreende o desenvolvimento de atividades que contemplam o tripé ensino, pesquisa e extensão. Essas atividades devem ser exercidas sob uma dimensão ética, abarcando projetos sociais, econômicos e culturais, com rigor científico e intelectual (UNESCO, 1998).

Os professores enfermeiros demonstraram compreender a função primordial da universidade pública como instituição social, e reconheceram o desenvolvimento 
do ensino, da pesquisa e da extensão como atividades que denotam a sua responsabilidade social: "Proporcionar retorno ao investimento que a sociedade faz nesse tipo de instituição" (PE 28); "Ensinar, pesquisar e fazer extensão com impacto de retorno para a sociedade” (PE 16).

Sobretudo, os professores enfatizaram na atividade de pesquisa o protagonismo proporcionado à formação do enfermeiro: "Fazer pesquisa para alavancar a profissão, com protagonismo ao curso de enfermagem e a formação do enfermeiro"(PE 29).

Corrobora com esses achados, um estudo realizado com professores enfermeiros em uma Instituição Federal de Ensino Superior, localizada no Sul do Brasil, na qual os investigados posicionaram-se favoráveis ao desenvolvimento de pesquisas na universidade com a finalidade do aperfeiçoamento na construção da profissão de enfermeiro (Sebold e Carraro, 2013).

Para Nóvoa (2015), a pesquisa universitária deve consolidar os laços entre a educação e a ciência, construindo uma educação de base que possibilite a professores e alunos os instrumentos de conhecimento e de autoconhecimento necessários, visando atingir resultados em um público mais alargado.

$\mathrm{O}$ fato de o professor enfermeiro ser pesquisador de seu próprio campo pode contribuir na formação de enfermeiros competentes e conscientes da dimensão de sua intervenção no contexto social (Lima e Santos, 2011), o que presume possibilitar o avanço na produção do conhecimento e o envolvimento do aluno na aprendizagem para além da técnica.

Com esse sentido, a pesquisa universitária passa a ser parte inerente do trabalho acadêmico, com a finalidade não somente de formação profissional, mas de responsabilidade social (Giroux, 1997). Nessa linha de raciocínio o conhecimento produzido por professores enfermeiros terá valor público e social, pertencendo à esfera dos direitos humanos e dos projetos civilizacionais, mediando o ensino sob um processo coletivo e articulado.

Para os professores enfermeiros, a universidade pública deve ter o comprometimento com o ensino e a formação de recursos humanos, visando satisfazer as demandas sociais e de saúde pública: "Desde que foi criada a função primordial da universidade pública é o ensino" (PE 13); "Formar o enfermeiro objetivando contribuir em melhorias na qualidade de vida da população” (PE 26).

Em um estudo realizado com professores enfermeiros de uma universidade pública da região Centro Oeste do Brasil, evidenciou-se a concepção de que o ensino de enfermagem deve estar voltado a atender às necessidades da clientela do sistema público de saúde (Pereira e Chaouchar, 2010).

À universidade compete a missão de formar pessoas com alto sentido cultural, moral e político de cidadania, e de contribuir, em sua esfera de possibilidades e em seus limites, para a solução de problemas da coletividade (Dias Sobrinho, 2015).

Formar enfermeiros significa formar este profissional, importante trabalhador da área da saúde, para além do suprimento da demanda de mercado, o que abrange contribuir efetivamente para mudanças de realidades sociais que estão postas.

Vale ressaltar que as exigências para a formação do enfermeiro com vistas a satisfazer as necessidades do sistema público de saúde estão recomendadas nas 
diretrizes curriculares nacionais para os cursos de graduação em enfermagem (DCN/ $\mathrm{ENF} / 2001)$ desde o início deste século (Brasil, 2001).

Acredita-se que, para os professores enfermeiros, participar da formação do enfermeiro na perspectiva de sua relevância social, enquanto profissão a ser exercida na enfermagem, é um desafio, uma vez que compreende a prática do esforço do trabalho docente não somente individual, mas coletivo, o qual depende da construção de conhecimentos relevantes e inovadores que se inserem nas instituições de ensino.

Os professores enfermeiros expressaram consentir com a função hegemônica contemporânea da universidade pública como organização social, o que se relaciona ao envolvimento docente no paradigma do produtivismo acadêmico.

Alguns professores lamentaram sobre a demanda excessiva de trabalho que tem de cumprir na universidade pública em que atuam: "É um volume de trabalho envolvendo ensino, pesquisa e extensão. Penso que peco na questão do ensino" (PE 22).

Outros demonstraram a importância do empenho da dedicação docente na produção científica em detrimento ao ensino, objetivando a competitividade internacional e a captação de recursos financeiros para a universidade: "O docente tem que se dedicar nas suas pesquisas para que essas tenham condiçôes de competitividade com a produção cientifica internacional" (PE 7); "A moeda de troca dentro da universidade são pesquisas, quando você vai progredir na carreira; assumir cargos; solicitar recursos, sejam materiais, financeiros ou humanos" (PE 16).

Em um estudo realizado com professores enfermeiros de três instituições de ensino superior da cidade de São Paulo, os investigados consideraram as atividades de ensino subsumidas à pesquisa (Leonello e Oliveira, 2014).

Para Chauí (2003) a perspectiva da universidade pública enquanto organização social carrega em sua estrutura a dinâmica ideológica do poder e controle social, que está em estreita conexão com a indústria cultural. Nessa perspectiva, os professores universitários para se fazerem reconhecidos na academia, inserem-se na lógica de um produtivismo acadêmico exacerbado (Nóvoa, 2015).

Ressalta-se que no Brasil, proliferam em universidades públicas organismos de gestão de atividades diversas, que buscam a captação de recursos e a intermediação com corporações externas no desenvolvimento de pesquisas (Dias Sobrinho, 2014).

Especialmente quanto à pesquisa no campo da enfermagem, nos últimos anos, constatou-se por meio dos índices bibliométricos e de rankings um aumento significativo da produção científica no país, sendo o grande desafio dos pesquisadores conseguirem a excelência, produzindo e publicando evidências em revistas nacionais e internacionais reconhecidas pela comunidade científica (Marziale, 2012).

Acredita-se que ninguém deva ser contra o reconhecimento de uma universidade pública quanto à excelência internacional em termos de produção científica, mas nessa lógica valorizam-se reflexões sobre a repercussão desse projeto quando suscita em produtivismo acadêmico.

Se por um lado o produtivismo acadêmico enfraquece as bases da profissão acadêmica (Nóvoa, 2015), por outro, é atingindo e superando metas de produtividade que se tem acesso aos parcos recursos disponíveis para o financiamento de pesquisas, principalmente no campo das ciências humanas (Domingues, 2013). 
No que se refere às pesquisas produzidas no campo da educação em enfermagem, espera-se que atinjam metas de produtividade, mas que se constituam sob princípios éticos e de justiça social, e que seus resultados sejam aplicados no aprimoramento e fortalecimento da assistência à saúde e na formação do enfermeiro.

Em relação à organização da universidade pública, em que atuam os professores, foram apontados aspectos que consideraram interferir no seu DPD. Alguns entrevistados manifestaram reconhecer a estrutura física da universidade e a oportunidade de cursos de formação pedagógica como fatores contribuintes para o DPD: "A infraestrutura influencia bastante. Temos tido bons laboratórios sociais que favorecem a questão da formação profissional" (PE 1); "Eu relaciono o DPD as oportunidades de cursos de preparação pedagógica” (PE 15).

De acordo com García (1999), o DPD compreende o conhecimento e envolvimento dos professores com a organização e estrutura da instituição de ensino em que atuam. Requer a formação dos mesmos sobre o ensino em relação aos conteúdos e às diferentes maneiras de ensiná-los, assim como se relacionará à profissionalidade docente, a qual abrange os saberes que propagam as capacidades de ação individual e coletiva, e de autonomia institucional que atingem intrinsecamente o próprio professor, enquanto profissional e sujeito que aprende.

No decorrer de toda a carreira docente, espera-se que os professores tenham oportunidades de participar de uma variedade de atividades de ações formativas indutoras de processos de revisão, renovação e aperfeiçoamento do seu pensamento e da sua ação, e, sobretudo, do seu compromisso profissional (Day, 2001), o que envolve a sua educação contínua (Nóvoa, 2009).

Vaillant e García (2015) consideram que todo sistema de DPD deve ser capaz de transformar e tornar o docente um facilitador da educação, ao longo de sua vida profissional. Os professores enfermeiros demonstraram conceber o DPD como elemento que abarca a carreira docente: "O DPD é a carreira do professor, porque eu trago para a graduação, para a docência que eu exerço, o que eu fui e o que eu sou. Eu trago a minha visão de mundo, as minhas experiências, aquilo que eu acredito, aquilo que eu quero formar" (PE 17).

O estudo realizado com professores enfermeiros por Madeira e Lima (2010) identificou a experiência profissional docente como ferramenta contribuinte na habilidade para desempenhar o ensino de enfermagem.

Acerca dos professores enfermeiros universitários, acredita-se ser possível associar o DPD às experiências adquiridas por estes no decorrer da profissão, sejam na iniciação ao ensino de graduação em enfermagem ou no desempenho de práticas assistenciais que competem ao trabalho do enfermeiro.

Em relação às experiências adquiridas no desempenho da profissão de enfermagem e suas contribuições para o exercício da docência, alguns professores demonstraram serem esses fatores contribuintes para o DPD: "Entendo que a minha experiência profissional me preparou para a docência, sendo que trabalhei em hospital e em pronto atendimento" (PE 23); "A prática profissional e o exercício da docência são pra mim sempre muito articuladas" (PE 9).

Esses relatos podem ser associados aos estudos de Rodrigues e Mendes Sobrinho (2008) e McNamara, Roat e Kemper (2012), os quais apontaram a ex- 
periência da prática assistencial como fator fundamental no desenvolvimento do trabalho docente.

Conforme Vaillant e García (2015), o DPD é um processo contínuo, sistemático e organizado, que abrange toda a carreira docente. García e Vaillant (2016) afirmam que o fato de o DPD abranger a carreira docente corresponde ao princípio da diversidade, posto que, os professores passam por diferentes estágios, com interesses e estilos muito diversificados de aprendizagem, envolvidos por várias crenças e ideias. Ainda, este princípio pode ser concluído pelo da continuidade, no qual qualquer oportunidade pode servir para iniciar um processo de DPD, desde que seja estabelecido um itinerário de metas.

Compreende-se que o trabalho diário construído pelos professores enfermeiros na universidade pública promovem, nos mesmos, o seu DPD, visto que aprendem a partir dele. Contudo, a profissão de professor enfermeiro tem uma intenção árdua, dado que sua conotação é ampla, pois ser enfermeiro é atuar no cuidado, e professor enfermeiro é formar aquele que futuramente irá exercer o cuidado, o que exige conhecimentos diversificados, com fundamentação pedagógica e teórica específica sobre aquilo que se ensina.

\section{O DPD E AS ATIVIDADES ACADÊMICAS E DIDÁTICAS QUE ENVOLVEM O EXERCÍCIO DA DOCÊNCIA NO ENSINO DE ENFERMAGEM}

O DPD integra o compromisso pessoal do professor, bem como a disponibilidade para aprender a ensinar (García, 2009). Deve estar conectado a um processo abrangente, com foco na melhoria da aprendizagem dos alunos (García e Vaillant, 2016). Para acontecer junto ao ensino, é preciso que as propostas teóricas de formação sejam construídas dentro da profissão, e que se promovam novos modos de organização, reforçando a dimensão pessoal e a presença pública dos professores (Novóa,2009).

García (2009) aponta a inovação curricular como agente de dimensão pessoal e pública dos professores, uma vez que, o currículo contém instrumentos que privilegiam o desenvolvimento profissional para o ensino, no que concernem as atividades desenvolvidas na escola, no ambiente de aula, no planejamento e na avaliação das estratégias de aprendizagem.

De acordo com Sacristán e Gómez (1998), o tema currículo somente terá um papel relevante no DPD quando trabalhado junto aos professores, levando-se em conta as suas formas de existência, sendo elas o currículo prescrito e o explícito. $\mathrm{O}$ currículo prescrito, também denominado projeto pedagógico (PP), refere-se a um plano escrito e materializado sob um texto, em que os professores ordenam o que ensinam. O explícito relaciona-se à expressão de uma intenção e do conteúdo, que representada pelo pensamento social e pela cultura, envolve a escola, os alunos, e o que os professores falam que ensinam, concretizando-se naquilo que se ensina.

Os professores enfermeiros demonstraram conhecimento e envolvimento junto ao currículo do curso de enfermagem em que atuavam: "O currículo nos dá a diretriz porque é uma carta de intençóes. Ele sinaliza de que jeito nós queremos atingir o nosso produto que é o aluno bem formado" (PE 18); "Eu participo bastante do currículo porque acho que é importante a gente se situar no processo de discussão dele, até para encontrar nossa identidade dentro do contexto da formação" (PE 1). 
Um estudo realizado com professores enfermeiros de uma Universidade Federal do Piauí identificou a construção do currículo prescrito do curso como um marco de sustentabilidade das ações socioeducativas que envolvem o ensino, configurando-se desse modo como um instrumento de trabalho que sugere o que vai ser feito, para se chegar com segurança aos resultados desejados (Madeira e Lima, 2010).

Para Sacristán e Gómez (1998), o texto curricular não é a realidade dos efeitos convertidos em significados aprendidos, mas é um texto que tem sua importância, porque difunde códigos sobre o que deve ser o ensino na escola. Assim, o fato de os professores enfermeiros terem demonstrado conhecimento sobre o currículo tem um significado importante no meio acadêmico, em razão que, o currículo serve para orientar os professores no preparo dos estudantes de enfermagem.

Além de afirmarem conhecer o currículo prescrito, alguns professores relataram ter participado de sua construção: "Eu conheço o PP. Eu já li, tive contato e participei das reuniões de estrutura curricular" (PE 13); "Eu participei desde o início da formulação desse curriculo" (PE 2); "Eu conheço o currículo porque participei de algumas assembleias para a discussão do mesmo" (PE 23).

García (2011) afirma que quando os professores participam do planejamento do currículo seu compromisso cresce, assim como seu aprendizado.

$\mathrm{O}$ modo como se formula o currículo condiciona o mesmo. Segundo Sacristán e Gómez (1998), o texto deve ser reprodutor da cultura própria da escola, que tem certas finalidades intrinsecamente escolares e que presta naturalmente um peculiar serviço à socialização e à reprodução. Se tratando do ensino de enfermagem, entende-se que deve ser um projeto dinâmico, implicado no contexto social, econômico, político e cultural que envolve a formação do enfermeiro. Também, deve conter a elaboração e organização de materiais didáticos e decisões administrativas sobre como se desenvolverá o ensino de enfermagem.

Alguns professores demonstraram perceber o currículo como um projeto dinâmico, que propõe o uso de métodos de ensino ativos, promotores de um aprendizado crítico e reflexivo: "O PP é muito dinâmico. Nós temos uma proforma. Ele tem uma imagem objetiva de onde se quer chegar, mas o contexto é que determina o processo de formação" (PE 1).

Contudo, divergências quanto às opiniões positivas sobre o currículo foram evidenciadas: "O currículo tem fortalezas, mas tem fragilidades" (PE 2); "Tem algumas lacunas dentro do nosso currículo" (PE 7).

Os relatos podem ser relacionados às considerações de Sacristán e Gómez (1998), quando afirma que toda proposta de texto curricular é traduzida pelos leitores, sendo que ao interpretá-la podem ser enriquecidas e até subvertidas suas intenções. Parafraseando García (2011), identifica-se a necessidade de que no decorrer do desenvolvimento do currículo, a sua constante avaliação deva ser um processo colaborativo e compartilhado, entre os professores enfermeiros, visto que contrariamente divergências individuais sobre o mesmo podem acontecer, o que pode comprometer o funcionamento adequado das atividades acadêmicas que competem à universidade pública e ao ensino de enfermagem. 
Alguns professores enfermeiros demonstraram haver uma necessidade em relação ao compartilhamento de ideias sobre o currículo do curso: "Eu acho que compartilhar com outros colegas ajudaria muito, pois você não sabe exatamente o que acontece na sua área e nas outras disciplinas" (PE 22); "Nós não conseguimos nos reunir. Eu me sinto muito frustrada" (PE 18).

Com relação a essas falas, têm-se o estudo realizado com professores enfermeiros universitários por Backes et al. (2013), no qual verificou-se ser o currículo prescrito do curso de enfermagem uma formação de base requerida pelos docentes.

Os professores demonstraram perceber o currículo como elemento de instigação e divergências, em que se encontra explícito em seus relatos a necessidade de formação e discussão sobre o mesmo. Também expressaram entender o currículo como mecanismo contribuinte para o DPD: "O curriculo em si tem aspectos muito interessantes a serem trabalhados, mas eu sinto muita falta de ter um preparo, tipo uma educação continuada sobre o mesmo" (PE 28).

Estudo realizado com professores enfermeiros universitários por Mafra et al. (2013) constatou a necessidade de aproximação docente junto ao currículo do curso, para compreensão crítica da proposta pedagógica. Nessa perspectiva, concorda-se com as afirmações de Giroux (1997) apontadas há mais de duas décadas, quando alertou para o fato de que a visão sobre a construção social dos princípios que governam o projeto curricular é muito ignorada pelos professores. Desse modo, entende-se o currículo como uma proposta a ser trabalhada e adaptada nas diferentes realidades de temas e conteúdos que os professores enfermeiros devam atuar, sendo seu principal foco a proposição de mudanças e inovações no ensino de enfermagem.

Dias Sobrinho (2015) afirma que, na atualidade, as universidades públicas são pressionadas pelos empoderados núcleos internacionais, sendo constrangidas a ajustar seus currículos aos padrões norteadores dos rankings de avaliação. As exigências de conectividade do conhecimento e de instrumentalidade técnica da formação, ou seja, da capacitação profissional, impõem prioridades curriculares e disciplinares aderentes à ordem econômica. Porém, isso tem fortes impactos nos prestígios sociais e acadêmicos, assim como nas políticas de financiamentos, tais como importantes impactos na formação fragmentária e utilitarista nos estudantes. Acredita-se que, se as necessidades de formação dos professores enfermeiros sobre a compreensão dos princípios filosóficos que se inserem no currículo prescrito fossem atendidas, as competências docentes desempenhadas sob o suporte do mesmo fluiriam com mais facilidade de entendimento e aceitação.

A inovação curricular promove nos professores o DPD, uma vez que o currículo contém instrumentos que privilegiam o desenvolvimento profissional para o ensino (Gómez, 1998). O ensino promove o DPD, pelo motivo que engloba comunicação; tarefas acadêmicas; métodos e estratégias, assim como dimensões ocultas do processo de ensinar, ou seja, pensamentos e tomada de decisões dos professores e dos alunos (García, 1999).

$\mathrm{O}$ ensino requer que os profissionais que o exercem através da docência sejam devidamente preparados (García e Vaillant, 2016). Um ensino de qualidade exige professores de qualidade, qualificados e com conhecimentos que demonstrem destrezas para enfrentar a complexidade e as mudanças inerentes à docência, 
e comprometidos com sua profissão ao longo de toda a carreira docente (Flores, 2008). Dessa maneira, compreende-se que o desenvolvimento do ensino propicia o DPD e depende do exercício da docência, sendo esta última um processo ampliado que não envolve somente saber ensinar, mas o contexto e o ambiente em que o docente se insere.

O ensino depende da prática pedagógica exercida pelo professor. A prática pedagógica envolve as questões próprias da atividade educativa de ensinar, sendo que compreendem o que se ensina, para que se ensina e como se ensina (Almeida e Pimenta,2014). A prática pedagógica inclui a didática e a transcende (Franco, 2015).

A didática compreende a construção de conhecimentos que possibilitam a mediação entre o que é preciso ensinar e o que é necessário aprender; entre o saber estruturado nas disciplinas e o saber ensinável nas circunstâncias e nos momentos; e entre as atuais formas de relação com o saber e as novas formas possíveis de reconstruí-los, se estruturando nas possibilidades de mediação entre o ensino (Franco e Pimenta, 2016). Compreende-se que a didática é o que dá sentido ao ensino, o qual é exercido pelos docentes através da prática pedagógica.

Franco (2016) considera que nas práticas pedagogicamente construídas, há a mediação do humano, e não a submissão do humano a um artefato técnico previamente construído; também, a prática pedagógica deverá incorporar a reflexão contínua e coletiva, de forma a assegurar que a intencionalidade proposta será disponibilizada a todos os envolvidos. Assim, uma aula ou atividade de ensino torna-se uma prática pedagógica quando se organiza em torno de intencionalidades, bem como na construção de práticas que conferem sentido às intencionalidades.

Para Leal (2005), a efetivação do processo ensino/aprendizagem se concretiza mediante o seu planejamento. Os professores afirmaram ter dificuldades quanto à disponibilidade de tempo para prepararem antecipadamente suas atividades de ensino, em função de suas extensivas demandas acadêmicas na universidade: " $E u$ gostaria de ter mais tempo pra preparar as atividades de ensino, mas a demanda de trabalho é muito grande" (PE 23); "Eu não posso dizer que 100\% das minhas aulas eu preparo com antecedência" (PE 17).

Esses relatos podem ser relacionados às afirmações de García (2010), quando aponta para o fato de que a ascensão do professor a diferentes papéis em uma instituição escolar leva-o a afastar-se das atividades que envolvem o ensino. Conforme Dias Sobrinho (2015), os grandes impactos de demandas acadêmicas sobre a vida dos docentes universitários estão relacionados à irradiação e à consolidação da ideologia e da economia neoliberal da atual globalização. Considerando a demanda excessiva de trabalhos acadêmicos, houve professores enfermeiros que relataram estender suas horas de trabalho no aconchego de seus lares, visando cumprir seus compromissos com a universidade: "Eu levo trabalho daqui pra casa com muita frequência, inclusive nos finais de semana" (PE 7); "O processo de trabalho na universidade hoje realmente me ocupa fora dela, ou seja, em casa, nos finais de semana” (PE 17).

Um estudo que objetivou analisar as características do trabalho de professores enfermeiros no ensino superior de instituições paulistanas identificou, entre os investigados, queixas quanto às excessivas demandas de trabalho acadêmico (Leonello e Oliveira, 2014). 
O modelo universitário hegemônico no mundo está comprometido com a irradiação e a consolidação da ideologia e da economia neoliberal da atual globalização, sendo que nessa lógica, se fazem a ciência, a tecnologia e a inovação. Relaciona-se a isto um grande impacto de demandas acadêmicas, sobre a vida dos docentes universitários (Dias Sobrinho, 2015).

Nessa conjuntura, identifica-se o professor enfermeiro universitário como um indivíduo que consente com a economia neoliberal. Talvez isto se deva, porque está movido por interesses que o mantém na posição de docente, cabendo a ele cumprir as demandas acadêmicas que compelem à carreira universitária. Sobretudo, percebe-se o professor enfermeiro universitário tendencioso a imergir no contexto da proposta neoliberal a que se encontra a universidade pública atual, no que concerne a suprimação, da expertise acadêmica do ensino, da mediação de conhecimentos, e da aplicação dos resultados e processos de inovação no ensino de enfermagem.

Segundo Franco (2015), as práticas pedagógicas são carregadas de intencionalidade, que dirige e dá sentido à ação, solicitando uma intervenção planejada e científica sobre o objeto, com vistas à transformação da realidade social. Com esse propósito, Leal (2005) alerta para o fato de que a efetivação do processo ensino/ aprendizagem se concretiza mediante o planejamento do ensino, visto que é aquele que deverá contemplar a ementa da disciplina, os objetivos de ensino, os conteúdos, a metodologia e a avaliação (Leal, 2005). O plano de aula corresponde à expectativa sobre o que se intenciona ensinar (Vasconcellos, 2008).

Os professores enfermeiros admitiram nem sempre ter a rotina de realização de planos de aula: "A maior parte das minhas aulas tem plano" (PE 17); "De um modo geral eu faço plano de aula. Se eu não faço eu coloco os itens da aula na lousa" (PE 24); "Eu não faço plano de aula, mas eu faço algumas anotações que me ajudam" (PE 9).

De acordo com esses relatos, pode-se relacionar o estudo realizado por Alexandre e Cesarino (2014), envolvendo 60 professores enfermeiros de universidades de uma cidade do interior do Estado de São Paulo, o qual identificou que menos da metade do total de investigados realizavam planejamento de aula.

Segundo Almeida e Pimenta (2014), ensinar abrange conhecer o planejamento no qual uma disciplina se insere, e as ações pedagógicas e os recursos adequados para o alcance dos objetivos. Nessa perspectiva, García (2011) afirma que para desenvolver competência em uma determinada área, os professores devem organizar o conhecimento de forma a facilitar sua implementação.

García (2011) considera que para desenvolver a competência em uma determinada área os professores devem ter uma base sólida de conhecimento teórico, entendendo fatos e ideias no contexto dessa estrutura conceitual. Sobretudo, a aprendizagem dos alunos depende principalmente do que os professores conhecem e de como podem fazer acontecer o ensino (García, 2008).

Segundo García (2010), para saber ensinar, o conhecimento da matéria não é uma condição suficiente de qualidade, visto que existem outros tipos de conhecimentos que também são importantes, a saber, o conhecimento do contexto, dos alunos, de si mesmo e de como se ensina. Além de conhecer o conteúdo que ensinam, os professores devem ter conhecimentos: sobre onde e a quem ensinar, adaptando-se à matéria dos alunos e às condições particulares da instituição de 
ensino; psicopedagógico, que se relaciona aos princípios gerais do ensino, à aprendizagem dos alunos, ao ensino em pequenos grupos e à gestão de classes; e didático do conteúdo, o qual se constitui como elemento central do conhecimento do professor, representando a combinação adequada entre o conhecimento da matéria a ensinar e o conhecimento pedagógico e didático referido para como ensinar (García, 2011; Vaillant e García, 2015).

Nessa perspectiva, verifica-se a importância de que as atividades de prática pedagógica sejam fundamentadas por referenciais teóricos da educação. Evidências sobre o uso de referenciais teóricos da educação, como suporte no preparo de práticas pedagógicas, encontraram-se presentes nos relatos dos professores enfermeiros investigados: "David Paul Ausubel eu tenho trazido muito pra perto" (PE 19); "Eu não sou uma purista Freiriana mas gosto das colocações que o Paulo Freire faz" (PE 27); "Eu uso Vigotski como base teórico didática" (PE 21); "Atualmente tenho me aproximado muito mais da abordagem histórico crítica de Demerval Saviani” (PE 14).

Compreende-se que a fundamentação como suporte pedagógico para o preparo das atividades de ensino apoia-se em teorias elaboradas por autores da educação. Essas teorias, conhecidas como pedagógicas e de ensino, foram construídas com o propósito de apresentar respostas aceitas como referenciais pela coletividade, sendo que se relacionam a fatos históricos e influenciam nas decisões pedagógicas do ensino (Hengemühle, 2008).

Entende-se que as teorias pedagógicas servem de referência sobre o método utilizado na construção do processo de ensinar. As teorias de ensino enfatizam a complexidade e o valor do ensino, promovendo o DPD. Entre os investigados, houve relatos de professores enfermeiros que admitiram não utilizar teóricos da educação para fundamentar o preparo de suas práticas pedagógicas: "Não uso nenbum autor da educação para preparar minhas aulas" (PE 30); "Para preparar minhas aulas eu uso o referencial teórico específico da disciplina que eu ministro" (PE 15).

Atestou-se com esses relatos os estudos realizados com professores enfermeiros por Rodrigues e Mendes Sobrinho (2008) e Rodrigues et al. (2013). No primeiro constatou-se que os professores enfermeiros, em sua maioria, não fundamentam a sua prática pedagógica a uma teoria de ensino. No segundo os professores enfermeiros admitiram que algumas abordagens pedagógicas não estão bem definidas e compreendidas por eles, sendo que não têm domínio conceitual sobre teorias de ensino e pedagógicas, assim como não têm clareza sobre como e/ ou em que momento podem utilizar esses fundamentos pedagógicos no preparo e desenvolvimento de suas atividades de ensino.

Para Franco (2015), a prática pedagógica deverá atingir os fins propostos pelas intencionalidades, configurando-se sempre como uma ação consciente e participativa. Nesse sentido, compreende-se que a prática pedagógica exercida pelos professores enfermeiros somente se definirá como tal quando proporcionar envolvimento dos estudantes com o processo de aprender. Evidências sobre a tentativa de proporcionar uma prática pedagógica com sentido e intencionalidade, objetivando a reflexão e a participação dos estudantes envolvidos no processo de aprender esteve presente nas falas dos investigados. Alguns professores enfermeiros relataram utilizar estratégias de ensino atrativas e ativas no desempenho de suas 
aulas: "O que tentamos fazer na disciplina é utilizar algumas metodologias mais ativas. A gente faz laboratório, jogos de imagens e açôes, que não sei se são adequadas ou não" (PE 30); "Nas disciplinas que eu leciono, nós trabalhamos em mais professores, e procuramos fazer algumas dinâmicas utilizando estratégias lúdicas” (PE18).

No estudo de Madeira e Lima (2010), que investigaram os saberes docentes que alicerçam a prática pedagógica de docentes de enfermagem, identificaram-se professores que de forma original, e muitas vezes criativa, elaboram suas práticas pedagógicas em sala de aula. No estudo de Pereira e Chaouchar (2010), os professores enfermeiros investigados revelaram substituir a prática pedagógica tradicional por práticas mais dinâmicas, enfatizando ser esse um movimento que precisa de planejamento prévio.

Esses relatos também podem ser relacionados às recomendações do Art. $14^{\circ}$ das DCN/ENF/2001, no que se refere a assegurar que a estrutura do Curso de Graduação em Enfermagem ofereça atividades teóricas e práticas, permeando a formação do Enfermeiro, de forma integrada e interdisciplinar, e a implementação de metodologia no processo ensinar-aprender que estimule o aluno a refletir sobre a realidade social e a aprender estimulado por dinâmicas de trabalho em grupos que favoreçam a discussão coletiva e as relações interpessoais (Brasil, 2001).

Em contrapartida, os professores enfermeiros que relataram ainda aderir em suas práticas pedagógicas estratégias de ensino de cunho meramente tradicional: "Eu tento relacionar o conteúdo que eu ensino com a prática de enfermagem, para que eles deem importância para aquilo que estão aprendendo" (PE 13); "Ainda acontecem aulas tradicionais. Fazemos o arcabouço teórico, depois fazemos o exercício da prática" (PE18).

Colaboram com esses relatos, estudos científicos da literatura nacional e internacional. Os estudos realizados no Brasil por Alexandre e Cesarino (2014) e Draganov e Sanna (2016) evidenciaram a predominância no uso de práticas pedagógicas tradicionais por professores enfermeiros universitários. Um estudo americano realizado com 946 professores enfermeiros, com o objetivo de explorar os tipos de pedagogias inovadoras utilizadas na educação de enfermagem em todo o mundo, identificou que a abordagem convencional centrada no professor continua sendo o estilo pedagógico mais prevalente (Brown et al., 2009).

Vaillant e García (2015) alertam para o fato de que a abordagem de ensino, em que o modelo de relações que se estabelece é o de justaposição dos conteúdos, a qual primeiro vem a teoria e depois a prática, como ocasião para aplicar conhecimentos, proporciona uma formação basicamente acadêmica, conceitual e proposicional. Para Schön (2000), a formação profissional em diferentes áreas de uma forma cartesiana, sendo a teoria desvinculada da prática como consequência de uma sólida formação teórica, não permite o desenvolvimento de profissionais criativos que possam dar conta das diferentes demandas que a prática lhes impõe.

Conforme Vaillant e García (2015), as formas tradicionais de ensinar já não servem ao mundo contemporâneo, uma vez que tanto a sociedade como os estudantes têm mudado, haja vista que os lugares onde se aprende e os sistemas de acesso à informação têm se multiplicado.

Evidências relacionadas ao fato de criar mecanismos de mobilização de saberes em outros espaços educativos foram consideradas entre os professores enfermeiros investigados, quando declararam relacionar o que ensinam à pesquisa 
e aos projetos de extensão que desenvolvem: "As pesquisas e projetos de extensão que eu realizo têm relação com aquilo que eu ensino" (PE 2); "Eu tenho extensões e crio coisas com os estudantes junto às práticas nos serviços de saúde” (PE 9).

Esses relatos vão de encontro ao que está recomendado nos artigos $9^{\circ} \mathrm{e}$ $14^{\circ}$ das DCN/ENF/2001 (Brasil, 2001), no que concerne à educação superior em enfermagem consubstanciada pela articulação entre o ensino, a pesquisa e a extensão. Diante disso, relembra-se que a responsabilidade social é exercida pela universidade mediante o desenvolvimento das atividades que contemplam o tripé ensino, pesquisa e extensão (UNESCO, 1998). Assim, entende-se que é missão do professor enfermeiro universitário formar o enfermeiro sob a perspectiva da responsabilidade social.

Considera-se o fato de os professores enfermeiros investigados articularem o ensino às atividades de pesquisa e extensão um aspecto de destaque no curso de enfermagem, cenário desse estudo, tendo em vista serem essas atividades fundamentais na formação dos acadêmicos, haja vista que proporcionam mecanismos de mobilização de saberes construídos em diversos espaços educativos.

Concebendo o envolvimento entre o DPD e o ensino, os professores enfermeiros consideraram o primeiro como uma influência positiva no exercício da docência universitária, devendo-se a isso o benefício proporcionado ao segundo pela qualificação e amadurecimento profissional docente: "Eu acho que se eu não tivesse toda a trajetória de qualificação docente que tive, eu não seria a professora que sou hoje” (PE 14); "O embasamento teórico do mestrado e do doutorado me tornaram uma professora melhor" (PE 29).

As oportunidades de cursos de formação pedagógica e o desenvolvimento de autonomia na carreira docente envolvem uma aprendizagem contínua, interativa e acumulativa, que compreende o DPD (García, 1999). Assim, o DPD não é um momento, mas uma jornada; deve integrar o conhecimento disciplinar que os professores possuem sobre um determinado assunto e as habilidades educacionais necessárias para exercer a profissão docente (García e Vaillant, 2016); e envolve oportunidades que fortalecem as condições para exercer a profissão docente (Vaillant e García, 2015).

Contudo, os professores enfermeiros consideraram que o DPD pode influenciar negativamente no exercício da docência universitária, visto que os distancia do ensino pelas excessivas demandas administrativas que envolvem o trabalho acadêmico e dedicação prioritária à pesquisa: "O trabalho na universidade exige muitas responsabilidades que deixam o professor cansado para exercer o ensino" (PE 22); "A carreira docente exige dedicação com valorização na pesquisa, o que compromete a dedicação ao ensino" (PE 30).

Esses relatos podem ser relacionados às considerações de Dias Sobrinho (2014), o qual afirma que o ensino realizado por docentes aderidos ao neoliberalismo acadêmico, acontece em universidades públicas, mediante a gestão de atividades diversas, que buscam a captação de recursos e a intermediação com corporações externas, como o desenvolvimento de pesquisas, processos e produtos de inovação. Santos, Guilherme e Dietz (2015) reiteram afirmando que, devido a cada vez menor intervenção estatal na direção e financiamento das universidades públicas, e dos programas de investigação, a educação superior está cada vez mais à mercê da globalização hegemônica e do capitalismo neoliberal. 
Considerando a responsabilidade da universidade na formação integral de cidadãos-profissionais (Dias Sobrinho, 2015), evoca-se o professor, enquanto responsável pela ativação e o desenvolvimento dos processos de ensino (Vaillant e García, 2015).

Assim, percebe-se que as condições de trabalho dos professores enfermeiros atuantes em universidade pública são elementos mediadores de DPD, que podem intimidar ou alavancar as atividades que envolvem o exercício da docência universitária, beneficiando ou não o ensino de enfermagem.

\section{CONSIDERAÇÕES FINAIS}

Mediante a realização desse estudo, confirmou-se a premissa inicial que o motivou, identificando-se sob a ótica de professores enfermeiros atuantes em universidade pública que o DPD tem profunda relação com o exercício da docência no ensino de enfermagem.

Nessa perspectiva, afirma-se que o DPD exerce influência sobre o exercício da docência, beneficiando ou não o ensino de enfermagem; pois envolve a vida pessoal e profissional do professor enfermeiro; e o contexto organizacional da universidade pública, local em que exerce suas atividades acadêmicas.

Contudo, diante dessa análise, não foi possível listar os benefícios ou prejuízos, que o DPD de professores enfermeiros atuantes em universidade pública possa desencadear sobre o ensino de enfermagem, mas destaca-se que a identificação de um paradoxo entre os resultados, talvez seja o mentor para questionamentos e reflexões que possam ajudar a identificar esse resultado.

Perceberam-se entre o grupo investigado, professores empenhados no exercício da docência universitária, mas distanciados dos fundamentos pedagógicos que envolvem o ensino de enfermagem, especialmente no que concerne ao seu planejamento. Nesse sentido, imersos no contexto da proposta neoliberalista, sobrecarregados por extensivas atividades acadêmicas, que consentindo com a universidade neoliberal, suprimem o planejamento do exercício da docência em detrimento ao produtivismo acadêmico.

Visualizando o professor enfermeiro, inserido em uma universidade pública operacional, há uma preocupação quanto às influências que as condições de trabalho desse profissional possam desencadear sobre aquele que ele forma, que é o enfermeiro, profissional a ser formado sob princípios que deverão integrar ativamente os interesses humanos e sociais, e não apenas satisfazer o mercado empresarial.

Nessa conjuntura questiona-se: é possível o professor enfermeiro universitário, sem o tempo necessário para a dedicação ao ensino, não permitir que o exercício da docência seja fragilizado?

Não está sendo negado aqui, que o modelo universitário hegemônico no mundo atual, o qual comprometido com a irradiação e a consolidação da ideologia e da economia neoliberal é aquele que superando metas de produtividade permite o acesso aos parcos recursos disponíveis para o financiamento de pesquisas, especialmente no campo da enfermagem. Mas diante disso, se faz um convite ao professor enfermeiro para pensar sobre os possíveis reflexos dessa lógica sobre o ensino de enfermagem.

Contrariamente à lógica do produtivismo acadêmico, espera-se que o professor enfermeiro tenha voz ativa na academia, não simplesmente se curve a atender 
às demandas do mercado intelectual de maneira automática, mas que encontre mecanismos para dialogar com o mesmo, gerando conhecimentos de ponta que se constituam sob princípios éticos e de justiça social, o que envolve a formação do enfermeiro e a assistência de enfermagem na área da saúde. Também, que preserve a imagem da universidade pública que o acolhe, que como tal é uma instituição social de ensino, cuja função primordial é a formação integral de cidadãos-profissionais mediados pelo conhecimento que integre a formação humana social, a ética e a política, o que sob essa lógica filosófica sedia o exercício da docência no ensino de enfermagem. Talvez, o caminho percorrido para amenizar a influência exercida pelo DPD sobre o exercício da docência no ensino de enfermagem esteja na abertura de espaços de discussão sobre esse assunto entre os próprios professores enfermeiros.

Reconheceu-se como limitações do estudo a escassez de pesquisas envolvendo a temática DPD de professores enfermeiros universitários, nessa conjuntura inibindo comparações mais valiosas, e o cenário onde foi realizada a investigação, visto que o caráter opinativo dos professores enfermeiros universitários relacionado ao DPD em universidade pública pode divergir de acordo com o contexto da universidade, onde as experiências pedagógicas são pensadas e aplicadas.

\section{REFERÊNCIAS}

AGNELLI, J. C. M.; NAKAYAMA, B. C.M. S. Constituição docente do enfermeiro:

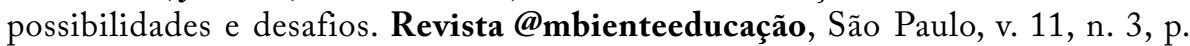
328-344, set./dez. 2018. Disponível em: http://publicacoes.unicid.edu.br/index. php/ambienteeducacao/article/view/544/617. Acesso em: 28 jan. 2020. https://doi. org/10.26843/ae19828632v11n32018p328a344

ALEXANDRE, K. C. R. S.; CESARINO, C. B. Formação e prática pedagógicas docente em cursos superiores de enfermagem em instituições particulares. Arquivos de Ciências da Saúde, São José do Rio Preto, v. 21, n. 1, p. 79-87, mar. 2014. Disponível em: http://repositorio-racs.famerp.br/racs_ol/vol-21-1/ID-577-21(1)-(Jan-Mar-2014). pdf. Acesso em: 22 fev. 2020.

ALMEIDA, M. I.; PIMENTA, S. G. Pedagogia universitária: valorizando o ensino e a docência na universidade. Revista Portuguesa de Educação, Braga, v. 27, n. 2, p. 7-31, jun. 2014. Disponível em: http://www.scielo.mec.pt/pdf/rpe/v27n2/v27n2a02. pdf. Acesso em: 22 fev. 2020. https://doi.org/10.21814/rpe.6243

BACKES, V. M. S. et al. Expressions of pedagogical content knowledge of an experienced nursing teacher. Texto Contexto Enfermagem, v. 22, n. 3, p. 804-810, set. 2013. Disponível em: https://www.scielo.br/pdf/tce/v22n3/en_v22n3a29.pdf. Acesso em: 2 set. 2020. https://doi.org/10.1590/S0104-07072013000300029

BOOTH, T. L. et al. Preparation of academic nurse educators. Nurse Education in Practice, v. 19, p. 54-57, jul. 2016. Disponível em: http://www.sciencedirect. com/science/article/pii/S1471595316300191. Acesso em: 20 dez. 2019. https://doi. org/10.1016/j.nepr.2016.04.006

BRASIL. Ministério da Educação. Resolução no 3, de 7 de novembro de 2001. Institui as Diretrizes Curriculares Nacionais do Curso de Graduação em Enfermagem. Brasília: 
Conselho Nacional de Educação, 2001. Disponível em: http://portal.mec.gov.br/cne/ arquivos/pdf/CES03.pdf. Acesso em: 15 dez. 2019.

BROWN, S. et al. The use of innovative pedagogies in nursing education: An international perspective. Nursing Education Perspectives, v. 30, n. 3, p. 153-158, 2009. CHAUÍ, M. S. A universidade pública sob nova perspectiva. Revista Brasileira de Educação, Rio de Janeiro, n. 24, p. 5-15, set.-dez. 2003. https://doi.org/10.1590/ S1413-24782003000300002

CUNHA, M. I. The theme of teacher education: trajectories and trends of the field in research and action. Educação e Pesquisa, São Paulo, v. 39, n. 3, p. 609-626, jul./set. 2013. Disponível em: http://www.scielo.br/pdf/ep/v39n3/en_aop1096.pdf. Acesso em: 20 jan. 2020. https://doi.org/10.1590/S1517-97022013005000014

DAY, C. Desenvolvimento profissional de professores: os desafios da aprendizagem permanente. Portugal: Porto, 2001.351 p.

DIAS SOBRINHO, J. Universidade e novos modos de produção, circulação e aplicação do conhecimento. Avaliação (Campinas), Sorocaba, v. 19, n. 3, p. 643-662, nov. 2014. Disponível em: http://www.scielo.br/scielo.php?pid=S141440772014000300007\&script=sci_abstract\&tlng=pt. Acesso em: 22 fev. 2020. https:// doi.org/10.1590/S1414-40772014000300007

DIAS SOBRINHO, J. Universidade fraturada: reflexões sobre conhecimento e responsabilidade social. Avaliação (Campinas), Sorocaba, v. 20, n. 3, p. 581-601, nov. 2015. Disponível em: http://www.scielo.br/pdf/aval/v20n3/1414-4077aval-20-03-00581.pdf. Acesso em: 22 fev. 2020. https://doi.org/10.1590/S141440772015000300002

DOMINGUES, E. Autoria em tempos de "produtivismo acadêmico". Psicologia em Estudo, Maringá, v. 18, n. 2, p. 195-198, abr./jun. 2013. Disponível em: http://www. scielo.br/pdf/pe/v18n2/a01v18n2.pdf. Acesso em: 20 jan.2020. https://doi.org/10.1590/ S1413-73722013000200001

DRAGANOV, P. B.; SANNA, M. C. Competências andragógicas dos docentes enfermeiros que atuam na graduação em enfermagem paulistana. Trabalho, Educação e Saúde, Rio de Janeiro, v. 14, n. 1, p. 155-182, abr. 2016. Disponível em: http://www. scielo.br/pdf/tes/v14n1/1981-7746-tes-14-01-0155.pdf. Acesso em: 22 fev. 2020. http://dx.doi.org/10.1590/1981-7746-sip00098

FLORES, M. A. La investigación sobre los primeiros años de enseñanza: lecturas e implicaciones. In: GARCIA, C. M. El professorado principiante: inserción a la docencia. Barcelona: Octaedro, 2008. v. 1. p. 28.

FONTANELLA, B. J. B. et al. Amostragem em pesquisas qualitativas: proposta de procedimentos para constatar saturação teórica. Cadernos de Saúde Pública, Rio de Janeiro, v. 27, n. 2, p. 389-394, fev. 2011. Disponível em: http://www.scielo.br/ pdf/csp/v27n2/20.pdf. Acesso em: 20 dez. 2019. https://doi.org/10.1590/S0102311X2011000200020 
FRANCO, M. A. S. Práticas pedagógicas de ensinar-aprender: por entre resistências e resignações. Educação e Pesquisa, v. 41, n. 3, p. 601-614, set. 2015. https://doi. org/10.1590/S1517-9702201507140384

FRANCO, M. A. S. Prática pedagógica e docência: um olhar a partir da epistemologia do conceito. Revista Brasileira de Estudos Pedagógicos, v. 97, n. 247, p. 534-551, set./dez.2016. Disponível em: http://www.scielo.br/pdf/rbeped/v97n247/2176-6681rbeped-97-247-00534.pdf. Acesso em: 21 dez.2019. http://dx.doi.org/10.1590/S2176$6681 / 288236353$

FRANCO, M. A. S.; PIMENTA, S. G. Didática multidimensional: por uma sistematização conceitual. Educação e Sociedade, Campinas, v. 37, n. 135, p. 539-553, jun. 2016. https://doi.org/10.1590/ES0101-73302016136048

GARCÍA, C. M. Formação de professores: para uma mudança educativa. Portugal: Porto, $1999.272 \mathrm{p}$.

GARCÍA, C. M. El professorado principiante: inserción a la docencia. Barcelona: Octaedro, 2008.294 p.

GARCÍA, C. M. Desenvolvimento Profissional Docente: passado e futuro. Revista de Ciências da Educação, São Paulo, n. 8, p. 7-22, jan./abr. 2009. Disponível em: $\mathrm{http} / /$ www.unitau.br/files/arquivos/category_1/MARCELO__Desenvolvimento_ Profissional_Docente_passado_e_futuro_1386180263.pdf. Acesso em: 28 jan. 2020.

GARCÍA, C.M. O professor iniciante, a prática pedagógica e o sentido da experiência. Formação Docente, v. 2, n. 3, p. 11-49, dez. 2010.

GARCÍA, C.M. Evaluación del desarrollo profesional docente. Barcelona: Davince, 2011.

GARCÍA, C. M.; VAILLANT, D. Desarrollo profesional docente: ¿Cómo se aprende a enseñar? Madri: Narcea, 2016.176 p.

GIROUX, H. A. Os professores como intelectuais: rumo a uma pedagogia crítica da aprendizagem. Porto Alegre: Artes Médicas, 1997.

GÓMEZ, A. I. P. A função e formação do professor no ensino para a compreensão: diferentes perspectivas. In: SACRISTÁN, J. G.; GÓMEZ, A. I. P. Compreender e transformar o ensino. 4. ed. Porto Alegre: Artmed, 1998. p. 353-379.

HENGEMÜHLE, A. Formação de professores: da função de ensinar ao resgate da educação. 2. ed. Petrópolis: Vozes, 2008.

LEAL, R. B. Planejamento de ensino: peculiaridades significativas. Revista Iberoamericana de Educación, Madri,v. 37,n. 3, p.1-6, 2005.https://doi.org/10.35362/ rie3732705

LEONELLO, V. M.; OLIVEIRA, M.A. C. Higher education in nursing: the faculty work process in different institutional contexts. Revista da Escola de Enfermagem da USP, São Paulo, v. 48, n. 6, p. 1091-1099, 2014. Disponível em: http://www.scielo.br/ pdf/reeusp/v48n6/0080-6234-reeusp-48-06-1093.pdf. Acesso em: 20 jan. 2020. https:// doi.org/10.1590/S0080-623420140000700018 
LIMA, P. G.; SANTOS, P. L. F. Solicitações profissionais e sociais de professores de cursos de enfermagem no Brasil. Interface - Comunicação, Saúde, Educação, Botucatu, v. 15, n. 39, p. 1097-1109, out./dez.2011. Disponível em: http://www.scielo. br/pdf/icse/v15n39/aop3111.pdf. Acesso em: 20 jan. 2020. https://doi.org/10.1590/ S1414-32832011005000030

LÜDKE, H. A. L. M.; ANDRÉ, M. Pesquisa em educação: abordagens qualitativas. 2. ed. São Paulo: EPU, 2018.112 p.

MCNAMARA, A.; ROAT, C.; KEMPER, M. Preparing nurses for the new world order: a faculty development focus. Nursing Administration Quartely, v. 36, n. 3, p. 253-259, set. 2012. Disponível em: https://www.ncbi.nlm.nih.gov/pubmed/22677966. Acesso em: 10 jan. 2020. https://doi.org/10.1097/naq.0b013e31825889ee

MADEIRA, M. Z. A.; LIMA, M. G. S. B. O significado da prática docente na constituição do saber ensinar das professoras do curso de enfermagem da Universidade Federal do Piauí. Texto \& Contexto - Enfermagem, Florianópolis, v. 19, n. 1, p. 7077, jan./mar. 2010. Disponível em: http://www.scielo.br/pdf/tce/v19n1/v19n1a08.pdf. Acesso em: 15 dez. 2019. https://doi.org/10.1590/S0104-07072010000100008

MAFRA, I. F. et al. Projeto político-pedagógico: fragilidades e potencialidades vividas por docentes universitários de enfermagem. Revista de Enfermagem da UERJ, Rio de Janeiro, v. 21, n. 3, p.361-365, jul./set. 2013. Disponível em: https://www.e-publicacoes. uerj.br/index.php/enfermagemuerj/article/view/7524/5444. Acesso em: 20 jan. 2020.

MARZIALE, M. H. P. Challenges of production and dissemination of the scientific knowledge of nursing. Acta Paulista de Enfermagem, São Paulo, v. 25, n. 3, 2012. Disponível em: http://www.scielo.br/pdf/ape/v25n3/en_v25n3a01.pdf. Acesso em: 15 dez. 2019. https://doi.org/10.1590/S0103-21002012000300001

MINAYO, M. C. S. O desafio do conhecimento: pesquisa qualitativa em saúde. São Paulo: Hucitec, 2014. 227 p.

NÓVOA, A. Professores imagens do futuro presente. Educa: Lisboa, 2009. 96 p.

NÓVOA, A. Em busca da liberdade nas universidades: para que serve a pesquisa em educação? Educação e Pesquisa, São Paulo, v. 41, n. 1, p. 263-272, jan./mar. 2015. Disponível em: http://www.scielo.br/pdf/ep/v41n1/1517-9702-ep-41-1-0263.pdf. Acesso em: 22 fev. 2020. http://dx.doi.org/10.1590/S1517-97022015400100301 ORGANIZAÇÃO DAS NAÇÕES UNIDAS PARA A EDUCAÇÃO, A CIÊNCIA E A CULTURA (UNESCO). Declaración mundial sobre la educación superior en el siglo XXI: visión y acción. Paris: UNESCO, 1998.

PEREIRA, W. R.; CHAOUCHAR, S. H. Identificação de novas práticas pedagógicas na percepção dos docentes de um curso de enfermagem. Ciência, Cuidado e Saúde, Maringá, v. 9, n. 1, p. 99-106, jan./mar. 2010. Disponível em: http://periodicos.uem. br/ojs/index.php/CiencCuidSaude/article/view/10533/5742. Acesso em: 20 dez. 2019. http://dx.doi.org/10.4025/cienccuidsaude.v9i1.10533

RODRIGUES, J. A. et al. Tendências Pedagógicas: Conflitos, Desafios e Perspectivas de Docentes de Enfermagem. Revista Brasileira de Educação Médica, Brasília, v. 37, 
n. 3, p. 333-349, 2013. Disponível em: http://www.scielo.br/pdf/rbem/v37n3/05.pdf. Acesso em: 20 jan. 2020. https://doi.org/10.1590/S0100-55022013000300005

RODRIGUES, M. T. P.; MENDES SOBRINHO, J. A. C. Obstáculos didáticos no cotidiano da prática pedagógica do enfermeiro professor. Revista Brasileira de Enfermagem, v. 61, n. 4, p. 435-440, ago. 2008 Disponível em: http://www.scielo.br/ scielo.php?script=sci_arttext\&pid=S0034-71672008000400006. Acesso em: 19 dez. 2019. https://doi.org/10.1590/S0034-71672008000400006

SACRISTÁN, J. S.; GÓMEZ, A. I. P. Compreender e transformar o ensino. 4. ed. Porto Alegre: Artmed, 1998.

SANTOS, B. S.; GUILHERME, M.; DIETZ, G. Da universidade à pluriversidade: Reflexões sobre o presente e o futuro do ensino superior. Revista Lusófona de Educação, v. 31, n. 31, p. 201-212, 2015.

SCHÖN, D. A. Educando o profissional reflexivo: um novo design para o ensino e a aprendizagem. Porto Alegre: Artmed, 2000.

SEBOLD, L. F.; CARRARO, T. E. Modos de ser enfermeiro professor no ensino do cuidado de enfermagem: um olhar heideggeriano. Revista Brasileira de Enfermagem, Brasília, v. 66, n. 4, p. 550-556, jul./ago. 2013. Disponível em: http://www.scielo.br/ pdf/reben/v66n4/v66n4a13.pdf. Acesso em: 20 jan. 2020. https://doi.org/10.1590/ S0034-71672013000400013

TONG, A.; SAINSBURY, P.; CRAIG, J. Consolidated criteria for reporting qualitative research (COREQ): a 32-item checklist for interviews and focus groups. International Journal for Quality in Health Care, v. 19, n. 6, p. 349-357, 2007. https:// doi.org/10.1093/intqhe/mzm042

VAILLANT, D.; GARCÍA, C. M. El ABC y D de La Formación Docente. Madri: Narcea, 2015. 174 p.

VASCONCELLOS, C. S. Processo de Planejamento. In: VASCONCELLOS, C. S. Planejamento: projeto de ensino - aprendizagem e projeto político-pedagógico. 18. ed. São Paulo: Libertad, 2008. p. 78-96.

ZABALZA, M. A. El Practicum y las prácticas en empresas: en la formación universitaria. Madri: Narcea, 2013. 189 p.

\section{SOBRE AS AUTORAS}

Kátia Pereira de Borba é doutora em ciências pela Universidade de São Paulo (USP). Professora da Universidade Estadual do Centro-Oeste (UNICENTRO).

E-mail:kborba@unicentro.br

Maria José Clapis é doutora em enfermagem pela Universidade de São Paulo (USP). Professora da Universidade Federal de Alfenas (UNIFAL). E-mail: maclapis@eerp.usp.br 
Conflitos de interesse: Os autores declaram que não possuem nenhum interesse comercial ou associativo que represente conflito de interesses em relação ao manuscrito.

Financiamento: $\mathrm{O}$ estudo foi financiado pela Coordenação de Aperfeiçoamento de Pessoal de Nível Superior (CAPES), Programa Pró-Ensino na Saúde, edital nº 2037/2010, intitulado "A formação de professores no contexto do SUS: políticas, ações e construção de conhecimento", vigente do ano de 2011 a 2015.

Contribuições dos autores: Administração do Projeto, Análise Formal, Conceituação, Curadoria de Dados, Escrita - Primeira Redação, Escrita - Revisão e Edição, Investigação, Metodologia, Obtenção de Financiamento, Recursos, Supervisão, Validação e Visualização; Borba, K. P. Administração do Projeto, Escrita - Revisão e Edição, Obtenção de Financiamento, Supervisão, Validação e Visualização: Clapis, M.J.

Recebido em 13 de março de 2020 Aprovado em 17 de setembro de 2020 